\title{
Flow-Injection Preconcentration of Chloramphenicol Using Molecularly Imprinted Polymer for HPLC Determination in Environmental Samples
}

\author{
Damian Kowalski, Ewa Poboży, and Marek Trojanowicz \\ Department of Chemistry, University of Warsaw, Pasteura 1, 02-093 Warsaw, Poland \\ Correspondence should be addressed to Marek Trojanowicz, trojan@chem.uw.edu.pl \\ Received 6 November 2010; Revised 27 December 2010; Accepted 27 January 2011 \\ Academic Editor: Dario Compagnone
}

Copyright ( $) 2011$ Damian Kowalski et al. This is an open access article distributed under the Creative Commons Attribution License, which permits unrestricted use, distribution, and reproduction in any medium, provided the original work is properly cited.

The residue of antibiotic chloramphenicol (CAP) is important issue for food quality control and also for the environmental monitoring. It is banned for use in food-producing animals and has very limited use in human medicine, because of its severe impact on human health. Determination of trace level of CAP in environmental samples requires a very sensitive analytical method and efficient preconcentration procedure. CAP can be efficiently preconcentrated in flow-injection system using flow-through reactor packed with molecularly imprinted polymer (MIP), but determination of CAP in eluate from MIP requires the application of chromatographic separation, which was made in reversed-phase HPLC system with UV detection. In optimized conditions the limit of detection for $100 \mathrm{~mL}$ sample in HPLC with offline preconcentration on MIP was evaluated as $0.66 \mathrm{mg} / \mathrm{L}$. In hyphenated FIA-HPLC system with zone sampling the LOD for developed method was evaluated as $15 \mathrm{ng} / \mathrm{L}$, which indicates the possibility of using it for analysis of environmental samples.

\section{Introduction}

The occurrence and impacts of various pharmaceuticals applied for human and veterinary use in the environment are emerging environmental issues in recent years. The presence of pharmaceuticals in the environment generally results from human and veterinary excretion of unmetabolized drugs passing into sewage systems and subsequent discharge of sewage effluents. Among variety of pharmaceuticals, the antibiotics are of special importance due to their extensive use in human therapy and veterinary medicine, as well as in promoting the growth of animals in livestock production [1-5].

Chloramphenicol (CAP) (2,2-dichloro- $N$ - $[(1 R, 2 R)-2$ hydroxy-1-(hydroxymethyl)-2-(4-nitrophenyl) ethyl] acetamide) (see Scheme 1) is an antimicrobial agent with restricted use, because it causes blood dyscresia and is reasonably anticipated to be a human carcinogen [6].

Numerous case reports have shown leukemia to occur after medical treatment for CAP-induced aplastic anemia.
Several studies show that its metabolite dehydrochloroamphenicol may be responsible for DNA damage [7], so CAP appears to be a gene toxin. CAP has been used since the 1950 s to combat a wide range of microbial infections. It has been also used in veterinary medicine as a highly effective and well-tolerated broad-spectrum antibiotic. It can be detected in blood serum, plasma, cerebrospinal fluid and urine. It can be released to environment and found in various waste streams. Half-life of CAP in soil is 4.5 days, while in water 10-20 days depending on $\mathrm{pH}$ and temperature.

CAP has been completely banned for use in foodproducing animals in many countries including European Union and USA, hence is treated as illegal antibiotic. A minimum performance limit which is required for the determination of CAP was set by EU at $0.3 \mu \mathrm{g} / \mathrm{kg}$ in all food of animal origin.

The most common method for routine determination of CAP is LC/MS, however usually in analysis of real samples with complex matrices, it has to be accompanied with cleanup step using most commonly solid-phase extraction. 


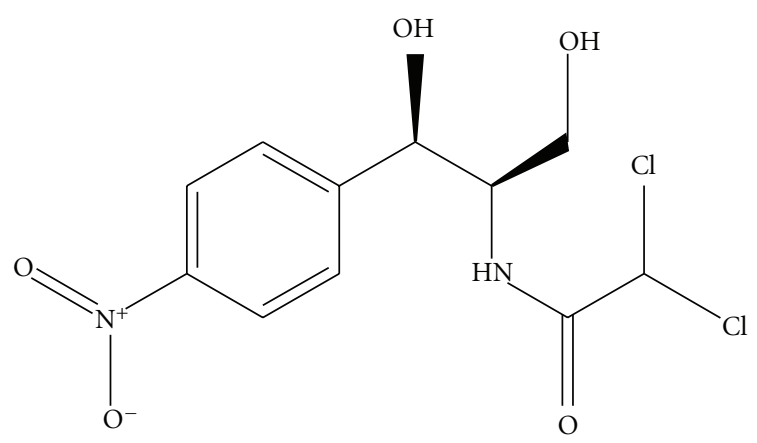

SCHEMe 1

Recently published papers reported development of methods for determination of CAP, for example, in honey [8], sewage treatment plants [9], in swine wastewater and environmental water samples [10], and also in herbs and grass [11]. For CAP determination the HPLC method with UV detection and SPE on C18 column was employed [12], and also GC/MS method [13]. Several flow injection methods with amperometric detection have been developed with various types of working electrodes [14-16].

For the same purpose in recent years also numerous immunochemical methods have been developed. Screening and confirmation in shrimp tissue samples using ELISA in combination with GC/MS and LC/MS was reported [17].

The application of molecularly imprinted polymers (MIP), laboratory-synthesized or commercially available, for the improvement of selectivity and limits of detection in the determination of CAP, can be a method competitive to the use of immunosorbents for the same purposes. In the way the MIP is used as packed bed in SPE cartridge as it was reported for HPLC determinations with UV detection $[18,19]$. The MIP for CAP was also employed as a solidphase dispersion sorbent for the CAP determination in fish tissues [20]. The commercial MIP in SPE cartridges was used for $\mathrm{LC}_{\mathrm{MS}} \mathrm{MS}^{2}$ determinations $[21,22]$. The flow through reactor packed with MIP beads was employed in the CAP determination with voltammetric detection for analysis of ophthalmic solutions and spiked milk samples [23]. Two other particular applications of MIP for CAP were reported in flow injection analysis (FIA) with luminescence detections. In fluorescent competitive flow through assay the MIP was packed to the spectrofluorimetric cell and the limit of detection (LOD) in such system was evaluated as $8 \mathrm{mg} / \mathrm{L}$ [24]. The FIA determination of CAP involving online preconcentration was recently reported in microfluidic system with chemiluminescence detection with unprecedented LOD level $2.4 \mathrm{ng} / \mathrm{L}$ for analyses in $50 \mu \mathrm{L}$ samples [25]. In conventional FIA system with chemiluminescence detection for $524 \mathrm{~mL}$ sample volume the LOD was evaluated as $30 \mu \mathrm{g} / \mathrm{L}$ [26].

The aim of this work was to investigate the possibility of application of commercial MIP preparation for CAP preconcentration in dynamic FIA system. Carrying out this step in flow through reactor may offer some advantages compared to conventional SPE syringes, including the mechanization of handling solutions, better control of eluent flow through the bed, and favorable elution in counter-flow direction. In the FIA system two different detections were examined, namely, spectrophotometric in UV range and amperometric. Due to limited selectivity of MIP sorption and possible bleeding, for the detection of CAP in eluate from the MIP bed the HPLC with UV detection was also applied. The optimized method was applied for CAP determination in spiked river water samples.

\section{Experimental}

2.1. Instrumentation. Electrochemical measurements were conducted on glassy carbon ( $3 \mathrm{~mm}$ diameter) working electrode, $\mathrm{Ag} / \mathrm{AgCl}$ was used as reference and platinum wire as auxiliary electrode. Cyclic voltammetry (CV) measurements were carried out with potentiostat $\mathrm{CHI}$ model $830 \mathrm{~B}(\mathrm{CH}$ Instruments Inc., Austin, Tex, USA).

The flow injection system with amperometric detection consisted of Knauer HPLC Pump model 64 and Autolab PGSTAT10 potentiostat (Eco Chemie, the Netherlands). The UV detection was carried out using flow detector Waters 2487 Dual $\lambda$ Absorbance. Tygon silicone tubings of $1.42 \mathrm{~mm}$ i.d. were used for pumping and PTFE tubing of $0.82 \mathrm{~mm}$ i.d. for connections; both were obtained from Cole Parmer (Chicago, Ill, USA). A two-position injection valve was obtained from Rheodyne (type 7010) (Rohnert Park, CA, USA). Injection loops of $100 \mu \mathrm{L}$ (amperometric system) and $20 \mu \mathrm{L}$ (UV system) were used throughout experiments. Manual solid-phase extraction procedure was carried out on a Vac Elut 20 Extraction Manifold obtained from Varian (Walnut Creek, Calif, USA).

Chromatographic determinations in offline mode were carried out using HPLC system HP Series II model 1090.

In FIA/HPLC hyphenated system with online sample preconcentration the peristaltic pump Alitea model U1 (FIALab Inc., Wash, USA) was used and Knauer HPLC 62 chromatographic pump. The Agilent column Zorbax Extended C-18 $(4,6 \times 150 \mathrm{~mm}, 5 \mu \mathrm{m})$ was used for HPLC separation.

2.2. Chemicals. Chloramphenicol (CAP), graphite nanofibers (95\%), and Nafion solution were purchased from Sigma-Aldrich (Steinheim, Germany). Methanol of HPLC grade used as eluent, was a product of Merck (Darmstadt, Germany). Phosphoric acid $85 \%$ of analytical grade used for preparation of carrier solution was from Chempur (Piekary Slaskie, Poland). Solid sodium hydroxide used for $\mathrm{pH}$ adjustment in preparation of phosphate buffer was from POCh (Gliwice, Poland).

MIP columns containing $25 \mathrm{mg}$ of polymeric bed were obtained from Sigma-Aldrich (SupelMIP SPE, MIP Technologies, Supelco).

A $30 \mathrm{mg} / \mathrm{L}$ CAP stock solution was prepared every second week by dissolving $0.015 \mathrm{~g}$ of compound in $500 \mathrm{~mL}$ deionized water and stored in a refrigerator. Standard solutions were prepared by suitable dilution of stock solution with water. The ultrapure water was from a Milli-Q ultrapure water purification system (Millipore, Bedford, Mass, USA). 


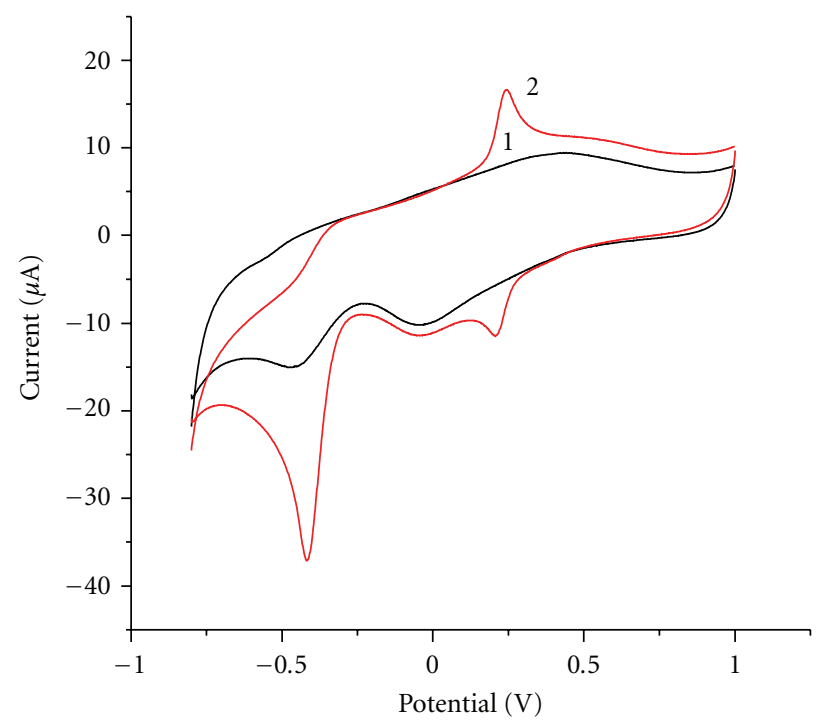

(a)

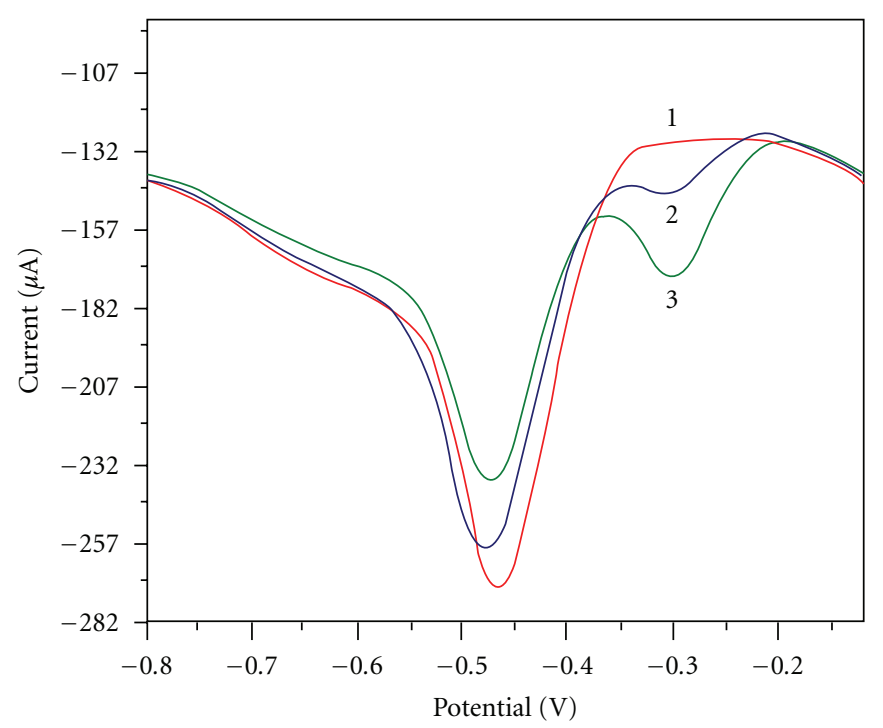

(b)

FIgure 1: (a) Cyclic voltammograms recorded for freshly made $0.5 \mathrm{mM}$ CAP solution in $0.1 \mathrm{M} \mathrm{H}_{3} \mathrm{PO}_{4}$ with scan-rate $10 \mathrm{mV} / \mathrm{s}$, using nonmodified glassy carbon electrode, and (b) linear-scan voltammograms recorded in the same conditions for freshly made (1), 3 days (2) and 20 days (3) after preparation of CAP solution.

2.3. Preparation of MIP Flow-through Reactor. The flow through reactor was prepared by slurry packing of MIP beads from SupelMIP SPE commercial cartridges à $25 \mathrm{mg}$. For preparation of the reactor $100 \mathrm{mg}$ of MIP bed prepared as aqueous suspension was trickled through SPE tube $(5 \mathrm{~mm}$ i.d.) in vacuum flow. Both outlets of reactor were plugged with polypropylene frits in order to prevent beads from washing out.

\subsection{Procedures}

2.4.1. Natural Sample Pretreatment. Samples of tap water were collected from the local water-supply system. River water was collected from Warsaw stretch of Vistula River. All samples were stored in refrigerator until the time of analysis. Prior to the preconcentration all samples were filtered on Whatman no. 42 filter papers.

2.4.2. Offline Sample SPE Extraction on MIP Sorbent. Conditioning of SPE cartridge was carried out by flushing it $5 \mathrm{~mL}$ methanol and $5 \mathrm{~mL}$ water, respectively. Afterwards aqueous sample was preconcentrated and bed was dried for $1 \mathrm{~min}$ in vacuum flow. The bed was washed with $1 \mathrm{~mL}$ of methanol to elute the analyte.

2.4.3. Online Sample Preconcentration in FIA/HPLC Hyphenated System. The procedure is analogous to that one mentioned above. Firstly, MIP flow through reactor was conditioned by pumping $5 \mathrm{~mL}$ of methanol and $5 \mathrm{~mL}$ of water, respectively, with flow rate $0.5 \mathrm{~mL} / \mathrm{min}$. Appropriate sample volume was preconcentrated consecutively (in flow rate up to $1.9 \mathrm{~mL} / \mathrm{min}$ ). Elution of analyte was carried out by pumping $1 \mathrm{~mL}$ of methanol through reactor with flow rate of $0.5 \mathrm{~mL} / \mathrm{min}$.
2.4.4. Chromatographic Determinations in Offline Mode. Prior to the injection, $1 \mathrm{~mL}$ of preconcentrated methanolic sample was diluted $3: 2$ with water.

\section{Results and Discussion}

Due to strong absorption of UV radiation and electroactvity of chloramphenicol, in this study on development of FIA systems for determination of trace level of CAP, the UV absorbance and amperometric detections of CAP were examined.

3.1. Amperometric Detection in FIA System. As it was mentioned already in Introduction, several reports were already published on the application of amperometric detection of CAP in FIA systems with different working electrodes [14-16]. The application of voltammetric detection with the use of a cylindrical carbon fiber microelectrode as the working electrode was also reported [23]. For a singlerun determination of CAP also a disposable electrochemical sensor with a Nafion coated screen-printed carbon working electrode was developed [27]. In each case the detection of CAP for analytical purposes was based on the fourelectron irreversible reduction of nitro group of CAP to the hydroxylamine derivative.

In this work as working electrode a conventional glassy carbon (GC) disk electrode of $3.0 \mathrm{~mm}$ diameter was employed. The cyclic voltammogram recorded for $0.5 \mathrm{mM}$ CAP solution in $0.1 \mathrm{M} \mathrm{H}_{3} \mathrm{PO}_{4}$ in potential range -0.8 to $+1.0 \mathrm{~V}$ is showed in Figure 1(a). It is in good agreement with voltammogram recorded using screen-printed carbon electrode for CAP in the same conditions [16], with cathodic peak of reduction of nitro group at $-0.45 \mathrm{~V}$. This working electrode was further employed in FIA measurements in 
the single-line manifold, using large-volume wall-jet cell. Based on recorded CV voltammograms and analogous measurements in hydrodynamic conditions for amperometric detection in flow measurements the polarization potential $-0.45 \mathrm{~V}$ was selected. In order to reduce the noise amplitude of baseline in determination of LOD the gravity flow was employed instead of the use of peristaltic pump. In measurements with the use of $0.1 \mathrm{M}$ phosphoric acid as carrier solution and for $100 \mu \mathrm{L}$ injection volume the LOD value for $\mathrm{S} / \mathrm{N}=3$ was evaluated as $71 \mu \mathrm{M}$. It is widely documented [28], that in many cases the modification of working electrode surface with the layer of carbon nanotubes (CNT) results in some electrocatalytic enhancement of the signal magnitude, hence in this work the GC electrode surface was covered with CNT by evaporation of suspension of CNT in Nafion on the electrode surface. This modification resulted in drop of LOD value down to $47 \mu \mathrm{M}$. The obtained $\mathrm{LOD}$ value is similar to that reported recently for detection of CAP in FIA system with amperometric detection using gold electrode with self-assembled monolayer of 2-mercapto-5methylbenzimidazole [14], but evidently poorer than those reported earlier for screen-printed carbon-based electrodes or boron-doped diamond electrode in FIA systems [15, 16, 27].

Although this detection was not further employed in this work due to poor LOD value, it was used for determination of stability of aqueous solutions of CAP. As it is showed in CV voltammograms in Figure 1(b), the height of cathodic peak for CAP is decreasing in time, what means the necessity of the preparation of fresh CAP solutions daily prior to the measurements.

3.2. UV Detection in FIA System. The liquid chromatographic determinations of CAP with UV detection reported in the literature were carried out at wavelengths 275$279 \mathrm{~nm}$ [18-20], which was in good agreement with our recorded spectrum for $3 \mathrm{mg} / \mathrm{L}$ aqueous solution of CAP, where maximum of absorption was observed at $278 \mathrm{~nm}$. This wavelength was used in this work for detection in FIA system with chromatographic detector Waters model 2487. The FIA signals recorded for CAP solutions using $20 \mu \mathrm{L}$ sample volume are showed in Figure 2. The well-reproducible blank signal ( $\mathrm{S}$ in Figure 2) resulted from injection of carrier in single manifold FIA system was taken into account in the calculation of LOD, taking into account both average blank signal value and its precision. For whole examined range of CAP concentration up to $300 \mathrm{mg} / \mathrm{L}$ the linear calibration plot was obtained with LOD $0.17 \mu \mathrm{M}(54 \mu \mathrm{g} / \mathrm{L})$. Because of much lower LOD obtained for CAP determination further measurements were carried out using UV detection.

\subsection{Preconcentration of CAP on Molecularly Imprinted} Polymer Bed. The commercially available MIP from MIP Technologies, which were designed for the chloramphenicol determination was already applied in the form of SPE cartridges, and it was employed for determination of CAP in milk-based matrices [21], and also in urine, plasma and honey [22] in LC/MS ${ }^{2}$ systems.

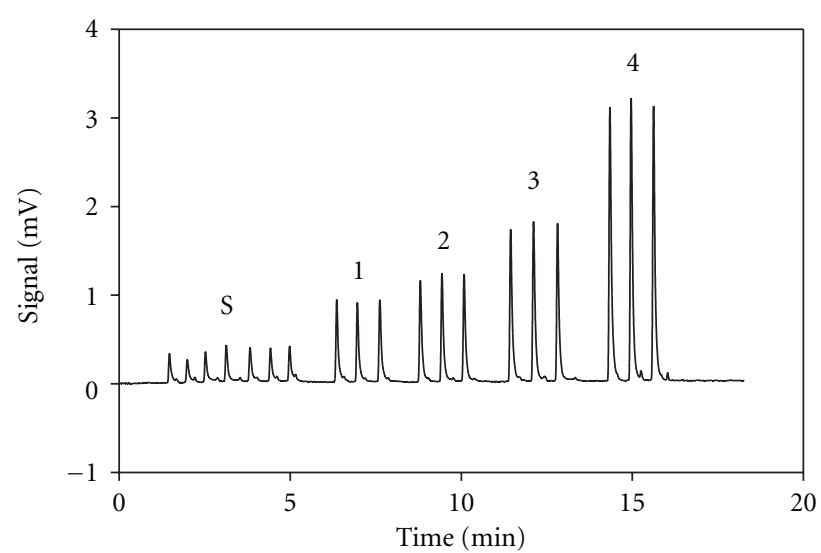

FIGURE 2: Flow-injection signals recorded for injected 60 (1), 90 (2), 150 (3) and 300 (4) $\mu \mathrm{g} / \mathrm{L}$ CAP solutions in water. Conditions: water used as carrier, flow rate $1 \mathrm{~mL} / \mathrm{min}$, injection volume $20 \mu \mathrm{L}$, UV detection at $278 \mathrm{~nm}$. S: signal corresponding to the instrumental blank which results from injection of water.

One of the aims of this study was to examine, if for detection of CAP preconcentrated on commercial MIP the direct UV detection in simple FIA system can be successfully applied. Already initial measurements with $25 \mathrm{mg}$ MIP cartridges showed a very significant bleeding of MIP bed in sequential cycles of rinsing the sorbent bed with deionized water and eluting with methanol. As the first step the MIP bed was conditioning according to manufacturer recommendation, then $10 \mathrm{~mL}$ of distilled water was aspirated through the sorbent bed using solidphase extraction vacuum manifold. After this, sorbent was dried during $1 \mathrm{~min}$ and washed with $1 \mathrm{~mL}$ methanol. The obtained eluate was evaporated in the argon stream and reconstituted with $1 \mathrm{~mL}$ water. The $20 \mu \mathrm{L}$ volume of obtained aqueous solution was injected into FIA system with UV detection. Figure 3 shows the FIA signal magnitude obtained after 8 consecutive repetition of this procedure, showing the evident presence of some components absorbing at $278 \mathrm{~nm}$. For the comparison, the dotted line in Figure 3 corresponds to signal obtained after injection into the FIA system the $20 \mu \mathrm{L}$ of standard $150 \mu \mathrm{g} / \mathrm{L}$ solution of CAP. This experiment convincingly indicates, that direct UV detection in eluate from the MIP bed without separation cannot be employed for the quantitative determination of preconcentrated CAP.

The presence of other than CAP components eluted from the MIP bed, in sequentially repeated blank procedure of washing bed with water and eluting with methanol, is confirmed by recorded chromatograms shown in Figure 4 . It was obtained in HPLC system with C18 column and water: methanol $(50: 50 \mathrm{v} / \mathrm{v})$ eluent. The chromatogram a corresponds to washing bed with $10 \mathrm{~mL}$ water and elution with $1 \mathrm{~mL}$ methanol, in $\mathrm{b}-10 \mathrm{~mL}$ of $15 \mu \mathrm{g} / \mathrm{L}$ CAP standard solution was loaded on the bed, and then washed with $1 \mathrm{~mL}$ methanol, that means 10-fold preconcentration of analyte. For comparison in $\mathrm{c}$ is shown chromatogram obtained for $150 \mu \mathrm{g} / \mathrm{L}$ CAP solution. It is evident that component(s) eluted as peak 1 on chromatograms will interfere in direct 


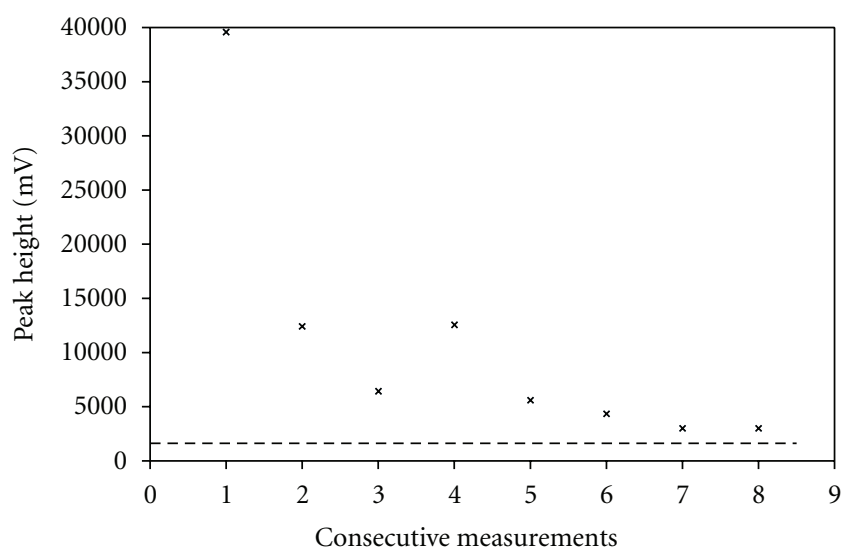

FIGURE 3: The changes of flow injection signal for flushing the MIP bed in SPE syringe with eight consecutive portions of $10 \mathrm{~mL}$ water, elution the MIP bed with $2 \mathrm{~mL}$ methanol after each flushing with water, evaporation, and reconstitution of evaporated samples in $1 \mathrm{~mL}$ water prior to the injection. Conditions of measurements are the same as in Figure 2. The dotted line shows the signal magnitude obtained for injection into the FIA system of a $150 \mu \mathrm{g} / \mathrm{L}$ solution of CAP in methanol.

detection of the eluate in the CAP determination hence the application of separation method for analysis of eluate from the MIP bed is indispensable.

For further HPLC determination of CAP in eluates from the MIP bed, the effect of different solvents used for reconstitution of the CAP eluted with methanol was examined, because as it is illustrated by chromatograms showed in Figure 5, the use of pure methanolic solutions causes some distortion of the signal shape by frontal peak broadening. This effect can be slightly reduced by the decrease of injected sample volume. It can be fully removed by the using of the HPLC eluent for reconstitution of evaporated elate from MIP bed. It was also observed that increase of the methanol content from 50 to $90 \%$ in injected CAP solutions in HPLC determination results additionally in about $20 \%$ decrease of the peak area. In optimized conditions for the determination of CAP using standard solutions, with injection sample volume $20 \mu \mathrm{L}$, a linear calibration plot peak area $v s$. CAP concentration in whole examined range up to $600 \mu \mathrm{g} / \mathrm{L}$ was observed. The LOD for $\mathrm{S} / \mathrm{N}=3$ was evaluated as $51 \mu \mathrm{g} / \mathrm{L}$.

In preconcentration of CAP from aqueous standard solutions using SPE cartridge with MIP, it was found that for the same amount of CAP 0.5 nanomole dissolved in different volumes ranging from 10 to $250 \mathrm{~mL}$, which was then loaded to the MIP bed with the same flow rate, a different recovery was obtained. This was observed for the same elution conditions, ranging from the complete recovery for $10 \mathrm{~mL}$ (recommended volume of eluent by the manufacturer), to about $60 \%$ recovery for initial sample volume $250 \mathrm{~mL}$. Concentration of the CAP in the solution, which was loaded onto MIP bed were in the range from 0.6 to $15 \mu \mathrm{g} / \mathrm{L}$. This can be attributed to slow kinetics of the sorption, important especially at low concentration level of analyte.

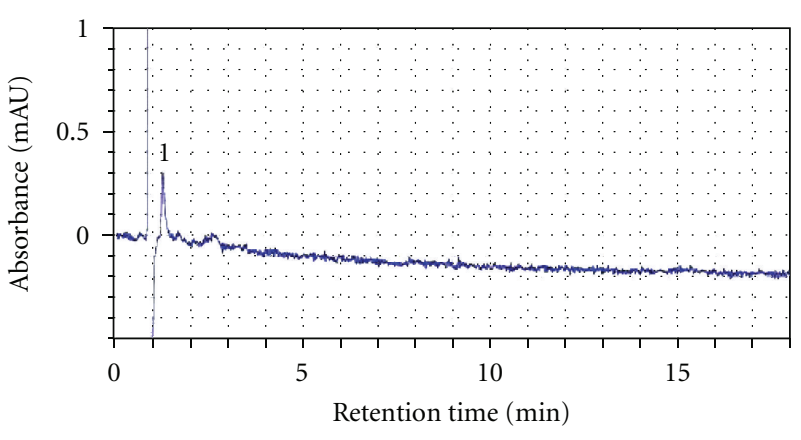

(a)

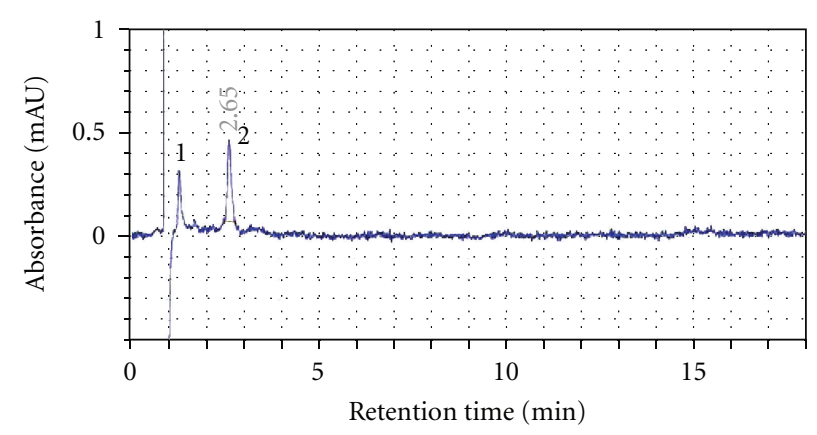

(b)

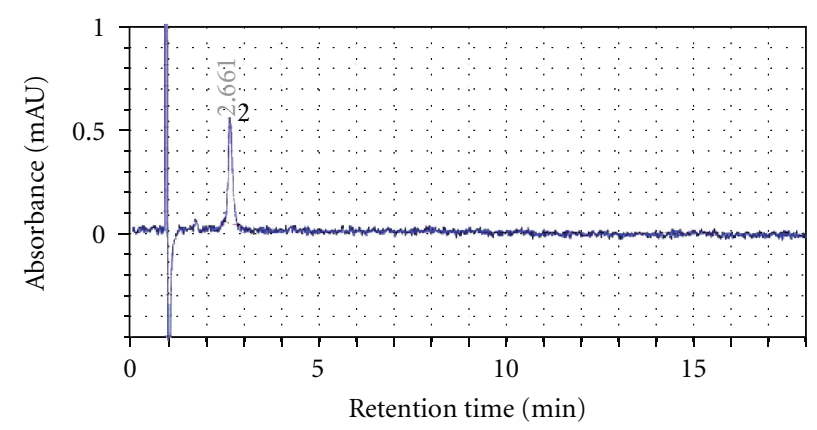

(c)

Figure 4: Chromatograms recorded in HPLC system with UV detection at $278 \mathrm{~nm}$ using as eluent water: methanol $(50 / 50 \mathrm{v} / \mathrm{v})$ mixture at flow rate $1 \mathrm{~mL} / \mathrm{min}$ and sample injection volume $20 \mu \mathrm{L}$. (a) blank solution obtained for flushing MIP bed with $10 \mathrm{~mL}$ water, elution with $1 \mathrm{~mL}$ methanol, evaporation and reconstitution in $1 \mathrm{~mL}$ water, (b) solution obtained by flushing MIP bed with $10 \mathrm{~mL} 15 \mu \mathrm{g} / \mathrm{L}$ CAP solution, elution with $1 \mathrm{~mL}$ methanol and reconstitution in $1 \mathrm{~mL}$ water, (c) injection of $150 \mu \mathrm{g} / \mathrm{L}$ standard solution of CAP. 1: unknown signal, 2: CAP. MIP used as $25 \mathrm{mg}$ bed in SPE syringe.

The same effect was examined for the application of flow through reactor with MIP prepared for carrying out preconcentration in the flow injection manifold, used later on in hyphenated FIA-HPLC system. For this purpose the flow through reactor was prepared using $100 \mathrm{mg}$ of beads taken from commercial MIP cartridges and packing them into the polypropylene tube of inner diameter $5 \mathrm{~mm}$. The standard solutions used for these measurements were 


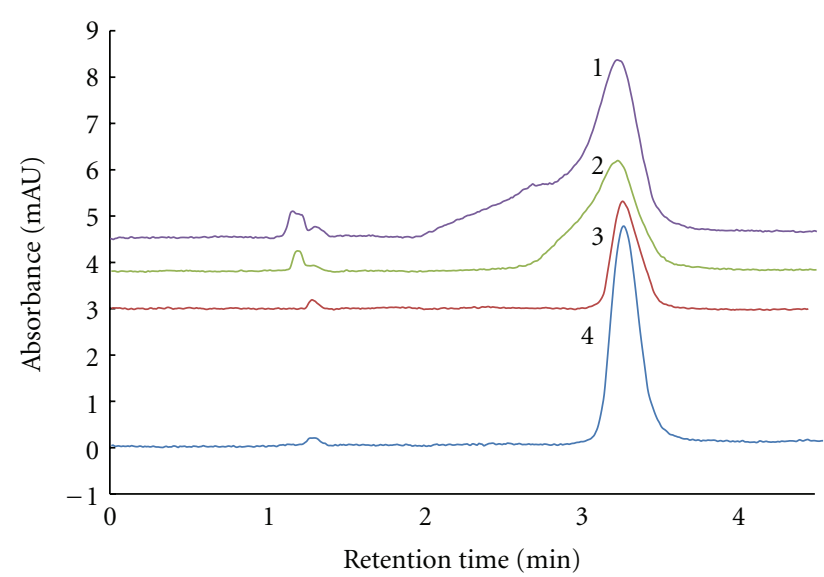

Figure 5: Effect of injected sample volume and methanol content in injected CAP solutions and on shape of peaks recorded in HPLC system with UV detection at $278 \mathrm{~nm}$. Injections of 20 (1) and $10(2) \mu \mathrm{L} 6 \mathrm{mg} / \mathrm{L}$ CAP solution in methanol, and injections of 10 (3) and 20 (4) $\mu \mathrm{L}$ of $3 \mathrm{mg} / \mathrm{L}$ CAP solution in water: methanol $(50: 50 \mathrm{v} / \mathrm{v})$ mixture. Other conditions are the same as in Figure 4.

ranging from 0.6 to $60 \mu \mathrm{g} / \mathrm{L}$, and the loaded volume from 10 to $500 \mathrm{~mL}$. The analyte retained on the MIP beads was eluted with methanol in counter-flow mode to sample loading. The obtained results showed in Table 1 indicate satisfactory recovery in optimized conditions up to initial sample volume loaded to the sorbent bed $250 \mathrm{~mL}$. This indicates the possibility of obtaining enrichment factor about 250, which is of a primary importance for the CAP determination in trace level in environmental samples. The chromatogram recorded for standard $1.0 \mu \mathrm{g} / \mathrm{L}$ CAP solution preconcentrated from $100 \mathrm{~mL}$ sample is shown in Figure 6(b) (curve 1). In these conditions, taking into account the amplitude of the baseline noise $(\mathrm{N})$ the LOD for $\mathrm{S} / \mathrm{N}=3$ was determined as $0.66 \mu \mathrm{g} / \mathrm{L}$, while the limit of quantitation (LOQ) for $\mathrm{S} / \mathrm{N}=10$ as $2.2 \mu \mathrm{g} / \mathrm{L}$.

3.4. CAP Determination in Natural Water Samples. In spite of numerous restrictions in use of chloramphenicol in human and veterinary medicine, in numerous studies its presence was found in natural waters and wastes. Its content in ground water and lake water from Hubei province in China was found about $2 \mathrm{ng} / \mathrm{L}$ [10], while in water from river Han in Korea $31 \mathrm{ng} / \mathrm{L}$ [29]. Much higher level, incidentally up to $1.5 \mu \mathrm{g} / \mathrm{L}$ was found in effluent from industrial installation for treatment of dairy wastewater [30]. The maximum CAP level in sewage treatment plant effluents was reported as $0.56 \mu \mathrm{g} / \mathrm{L}$ [31], while in sewage treatment plants in China, in influent $31 \pm 16$, and in effluent $17 \pm 10 \mathrm{ng} / \mathrm{L}$ [9]

In analyses of environmental samples for the determination of trace analytes, the challenging task is not only the developing of sufficiently sensitive method, but also optimizing whole analytical procedure in order to eliminate interferences from matrix components. The sorption processes observed in molecularly imprinted polymers include not only selective binding of target analyte in cavity of polymer produced by employed template, but also nonspecific sorption of matrix components, for example, by hydrophobic interactions with polymer matrix, which are strengthened in aqueous conditions [32]. As it was demonstrated above, the application of direct UV detection of CAP in the eluate from MIP bed is not possible due to washing out of the sorbent beads some other notidentified, as yet, components than CAP. Therefore, it is necessary to apply some separation method, for example, as HPLC in this study, which can additionally separate target analyte CAP in eluates from MIP-based preconcentration of analyte from complex matrices. This is well illustrated by example chromatograms showed in Figure 6 for natural water samples. In both samples of tap and river water, in dead-volume of HPLC chromatograms a large absorbance is observed, that can be attributed to the presence of other organic components retained on MIP bed during the preconcentration run. There are also, especially in river water sample, numerous components eluted with particular retention time. The spiking of analyzed samples with CAP at $1 \mu \mathrm{g} / \mathrm{L}$ level, illustrates the potential of this method for real analytical application. It seems that for instance for analysis of river water samples, a further optimization of HPLC separation should be made for better separation of signal for CAP from partly overlapped signal with retention time $3.50 \mathrm{~min}$.

As it showed in Table 2, the recovery of CAP determination is slightly affected by matrix components in natural waters, compared to aqueous CAP standards, but for $100 \mathrm{~mL}$ sample volume, giving enrichment factor 100 , the obtained recovery above $92 \%$ can be considered as satisfactory.

3.5. Hyphenated FIA-HPLC System. The schematic of the final setup for this study with hyphenation of flow injection preconcentration with HPLC analysis is showed in Figure 7. The crucial factor in optimization of functioning of this system is to find the most favorable time delay for injection of $20 \mu \mathrm{L}$ sample with chromatographic injection valve since starting elution from MIP column. In order to do this, the concentration profile of eluted sample was recorded. The experimental data for this plot were obtained by sampling a $20 \mu \mathrm{L}$ volume from eluted $1 \mathrm{~mL}$ methanolic solution from MIP column every $30 \mathrm{~s}$ since the elution from the MIP column has started, and injecting this into HPLC setup. The obtained profile is showed in Figure 8(a). The maximum concentration in dispersed zone of $1 \mathrm{~mL}$ methanolic eluent was observed in sample segment taken after $775 \mathrm{~s}$, and this time delay was employed for measurements in hyphenated systems.

As one can expect this zone re-sampling step allows the injection of a much more concentrated sample than average concentration in whole volume of $1 \mathrm{~mL}$ methanolic eluent used for injection in offline mode measurement. Based on chromatographic signal recorded for $30 \mu \mathrm{g} / \mathrm{L}$ CAP solution (Figure 8(b)), based on the peak-height for $\mathrm{S} / \mathrm{N}=3$, the limit of detection was evaluated as $0.15 \mu \mathrm{g} / \mathrm{L}$. This was 


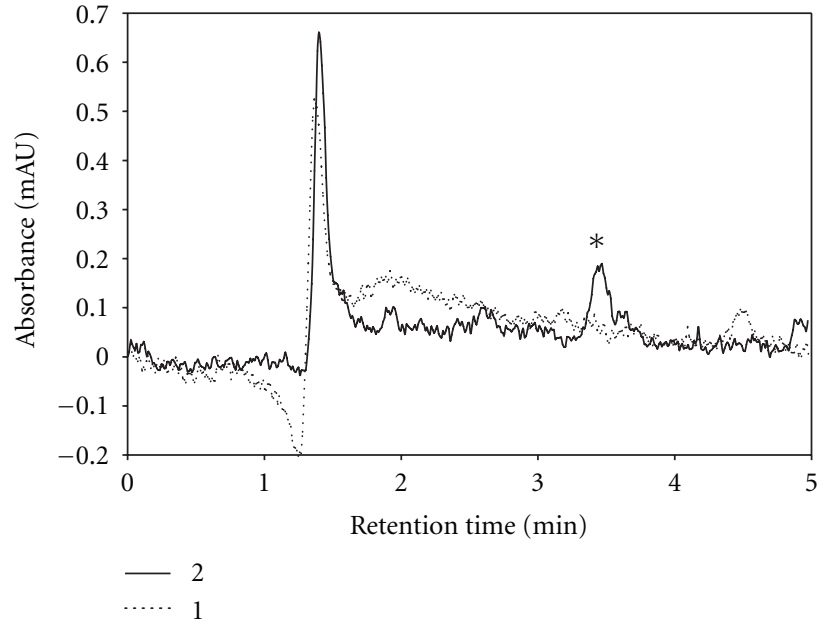

(a)

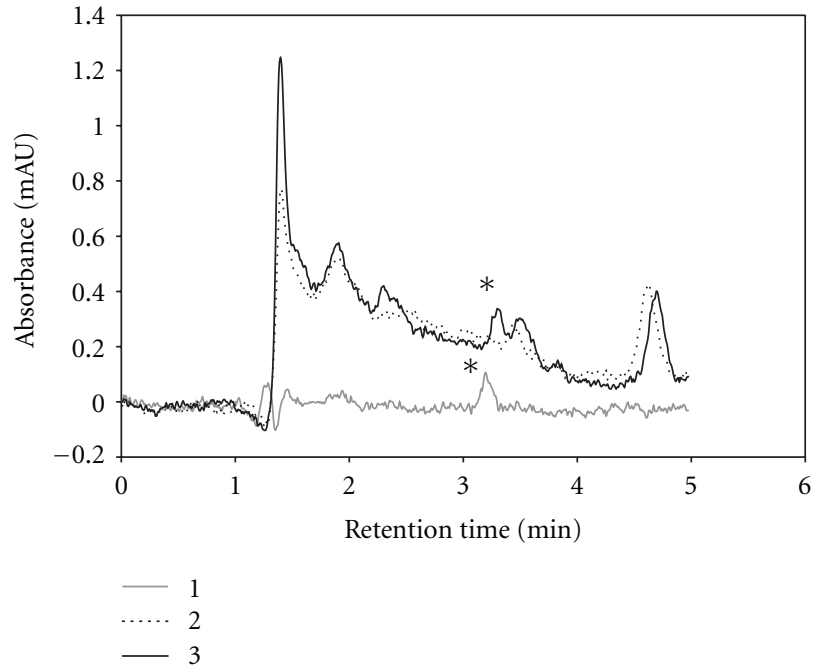

(b)

FIgURE 6: Chromatograms recorded in HPLC system with UV detection for eluates from preconcentration $100 \mathrm{~mL}$ samples in MIP flow through reactor, and elution with $1 \mathrm{~mL}$ methanol. Prior to the injection eluates diluted $3: 2$ with water, and injected 20 $\mu \mathrm{L}$. (a) 1: tap water, 2: tap water spiked with $1 \mu \mathrm{g} / \mathrm{L}$ CAP. (b) $1: 1 \mu \mathrm{g} / \mathrm{L}$ standard solution of CAP, 2: river water, 3: river water spiked with $1 \mu \mathrm{g} / \mathrm{L}$ CAP. Preconcentration carried out with flow rate $1.92 \mathrm{~mL} / \mathrm{min}$, elution with flow rate $0.36 \mathrm{~mL} / \mathrm{min}$. Asterisk indicates CAP peak.

TABLE 1: The recovery of CAP preconcentration from aqueous standard solutions on MIP flow through reactor in FIA system with UV detection. MIP reactor of $5 \mathrm{~mm}$ i.d. and $100 \mathrm{mg}$ MIP bed was used. The elution was carried out with $1.2 \mathrm{~mL}$ methanol.

\begin{tabular}{|c|c|c|c|c|c|}
\hline $\begin{array}{l}\text { Initial CAP } \\
\text { concentration, } \mu \mathrm{g} / \mathrm{L}\end{array}$ & $\begin{array}{l}\text { Initial volume of } \\
\text { loaded solution, } \mathrm{mL}\end{array}$ & $\begin{array}{c}\text { Enrichment } \\
\text { factor }\end{array}$ & $\begin{array}{c}\text { Flow rate of } \\
\text { preconcentration, } \mathrm{mL} / \mathrm{min}\end{array}$ & $\begin{array}{l}\text { Average } \\
\text { recovery, \% }\end{array}$ & $\begin{array}{c}\mathrm{RSD} \text { of } \\
\text { recovery, \% }\end{array}$ \\
\hline 30.0 & 10 & 8.3 & 0.5 & 105.0 & 2.9 \\
\hline 3.00 & 100 & 83 & 1.4 & 103.5 & 3.0 \\
\hline 1.20 & 250 & 208 & 1.9 & 104.6 & 4.4 \\
\hline 0.60 & 500 & 417 & 1.7 & 62.6 & 5.0 \\
\hline
\end{tabular}

TABLE 2: The recovery of CAP preconcentration on MIP flow through reactor in FIA system with UV detection for natural water samples spiked with known amounts of CAP. Preconcentration was carried out with flow rate $1.9 \mathrm{~mL} / \mathrm{min}$, and elution with $1.0 \mathrm{~mL}$ methanol at $0.48 \mathrm{~mL} / \mathrm{min}$. Flow-through reactor was used with $100 \mathrm{mg}$ MIP bed.

\begin{tabular}{|c|c|c|c|c|c|}
\hline Sample & Initial sample volume, $\mathrm{mL}$ & Added CAP, $\mu \mathrm{g} / \mathrm{L}$ & Enrichment factor & Average recovery, \% & RSD of recovery, $\%$ \\
\hline Tap water & 250 & 3.60 & 250 & 78.2 & 4.3 \\
\hline Tap water & 100 & 9.00 & 100 & 92.9 & 1.5 \\
\hline Tap water & 100 & 1.00 & 100 & 95.7 & 1.3 \\
\hline River water & 250 & 3.60 & 250 & 80.9 & 1.7 \\
\hline River water & 100 & 1.00 & 100 & 94.9 & 1.3 \\
\hline
\end{tabular}

obtained for 10 times preconcentration as initial sample volume for preconcentration was $10 \mathrm{~mL}$, while for evaluated earlier 100 times enrichment the LOD value will be $15 \mathrm{ng} / \mathrm{L}$, which seems to be satisfactory for analysis of environmental samples.

\section{Conclusions}

The determination of pharmaceutical residues in environmental and food samples is a challenging task in modern analysis. It is due to their ultra trace level and from other 




(a)



(b)

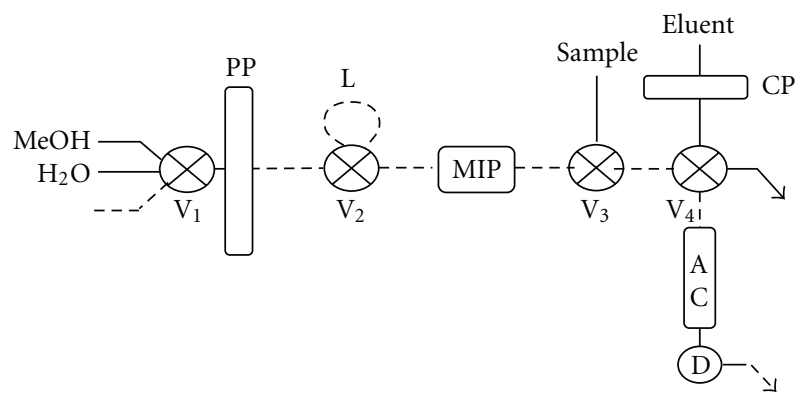

(c)

FIGURE 7: Schematic diagram of hyphenated FIA-HPLC system with UV detection for determination of CAP with online preconcentration on MIP in MIP bed washing (a), CAP preconcentration (b), and elution stage (c). Actual flow of analytes is shown by dotted line. PP: peristaltic pump, CP: chromatographic pump, $\mathrm{V}_{\mathrm{i}}$ : injection valves, AC: analytical column, MIP: flow through reactor with MIP, D: detector.

point of view of significant possible toxic and mutagenic effects for higher organisms, including humans. They require usually preconcentration of trace analyte and cleanup samples with complex matrices, what most commonly is carried out with solid-phase extraction methods.

A significant improvement in SPE sample treatment is carrying it out in flow injection systems, which simplifies the manipulation with solutions in different stages of whole procedure, and can then be utilized in design of mechanized or automated measuring systems. The application of MIP in SPE allows the obtaining certain selectivity of preconcentration process, but in complex matrices, as it was shown for determination of chloramphenicol in spiked

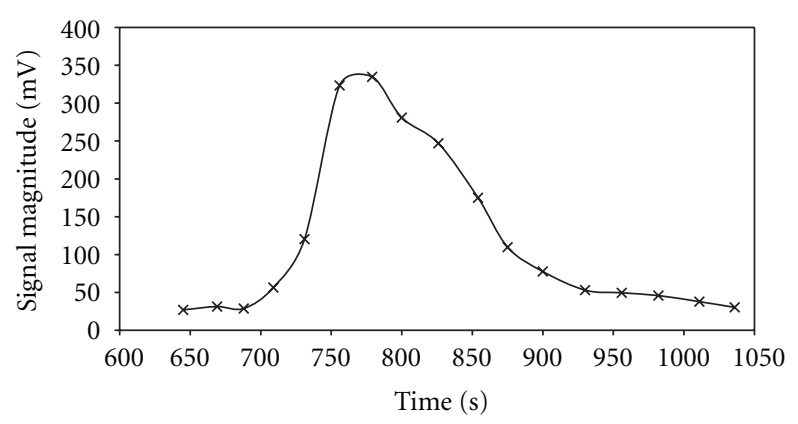

(a)

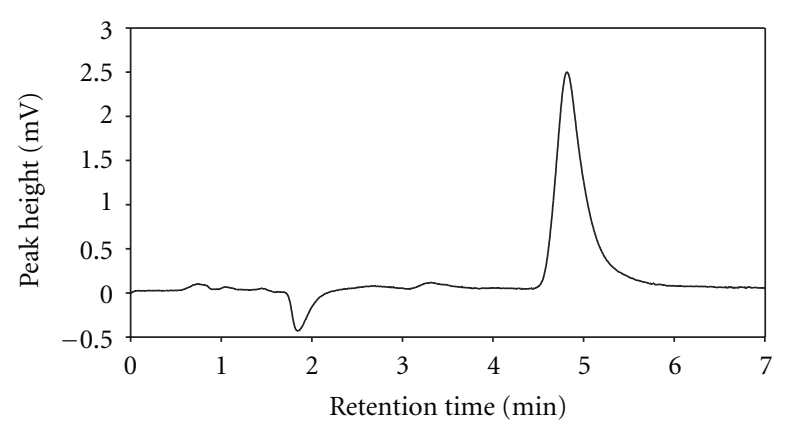

(b)

FIGURE 8: Concentration profile of $1 \mathrm{~mL}$ methanol sample used for elution of CAP from MIP column with flow rate $1.5 \mathrm{~mL} / \mathrm{min}$ (a) and chromatogram recorded in hyphenated FIA-HPLC system using re-sampling in $775 \mathrm{~s}$ since starting elution from MIP column with $20 \mu \mathrm{L}$ volume (b). In (a) preconcentrated $10 \mathrm{~mL}$ solution of $300 \mu \mathrm{g} / \mathrm{L}$ CAP. In (b) preconcentrated $10 \mathrm{~mL}$ solution of $30 \mu \mathrm{g} / \mathrm{L}$.

natural waters, this selectivity is not sufficient for application of simple flow detection without separation of components of eluates from MIP reactor. The obtained sub- $\mu \mathrm{g} / \mathrm{L}$ LOD level indicates a potential possibility of application of developed method for CAP monitoring in heavy-loaded industrial and agricultural wastes for environmental protection. In the hyphenated FIA-HPLC system where additionally zone resampling can be employed, using 100 times enrichment on MIP column, the limit of detection was evaluated as $15 \mathrm{ng} / \mathrm{L}$, which makes the developed method suitable for determinations of CAP in waters.

For the comparison of the developed method with methods reported earlier in the literature, the limits of detection are listed in Table 3. The developed method exhibits the best LOD value among other flow methods with different detections, and better values of LOD were reported only for sophisticated capillary electrophoretic method with LIF detection [34], and also one of reported surface plasmon resonance method [37]. Table 3 does not include applications of LC/MS methods in food and biological material analysis, where LOD values are evaluated in terms of content of CAP in analyzed material. Based on recent review [38] one can expect the possibility of application of developed method also for determination of CAP in biologicl samples. 
TABLE 3: The values of limits of detection (LOD) of chloramphenicol reported for different analytical methods.

\begin{tabular}{lccc}
\hline Method & LOD, $\mu \mathrm{g} / \mathrm{L}$ & Reference \\
\hline FIA with amperometric detection & 0.44 & 9.7 & {$[14]$} \\
FIA with amperometric detection & 24 & {$[15]$} \\
FIA with amperometric detection & 8000 & {$[16]$} \\
FIA with fluorimetric detection, and SPE-MIP & 500 & {$[24]$} \\
SIA-HPLC with UV detection & 0.019 & {$[33]$} \\
Microflow system with chemiluminescence detection and SPE-MIP & 0.015 & This work \\
FIA-HPLC with UV detection and online SPE-MIP & 4.3 & {$[23]$} \\
Voltammetry with offline MIP & 0.0016 & {$[34]$} \\
CE immunoassay with LIF detection & \multicolumn{2}{c}{1.2} & {$[35]$} \\
Immunoaffinity chromatography & 0.032 & {$[36]$} \\
SPR immunoassay & 0.00074 \\
SPR immunoassay & {$[37]$} \\
\hline
\end{tabular}

FIA: flow injection analysis, SIA: sequential injection analysis, SPE-MIP: solid-phase extraction with molecularly imprinted polymer, SPR: surface plasmon resonance, LIF: laser induced fluorescence.

\section{References}

[1] B. Halling-Sorensen, S. Nors Nielsen, P. F. Lanzky, F. Ingerslev, H. C. Holten Lützhoft, and S. E. Jorgensen, "Occurrence, fate and effects of pharmaceutical substances in the environment-a review," Chemosphere, vol. 36, no. 2, pp. 357393, 1998.

[2] E. R. Campagnolo, K. R. Johnson, A. Karpati et al., "Antimicrobial residues in animal waste and water resources proximal to large-scale swine and poultry feeding operations," Science of the Total Environment, vol. 299, no. 1-3, pp. 89-95, 2002.

[3] A. A. M. Stolker and U. A. TH. Brinkman, "Analytical strategies for residue analysis of veterinary drugs and growthpromoting agents in food-producing animals-a review," Journal of Chromatography A, vol. 1067, no. 1-2, pp. 15-53, 2005.

[4] K. G. Karthikeyan and M. T. Meyer, "Occurrence of antibiotics in wastewater treatment facilities in Wisconsin, USA," Science of the Total Environment, vol. 361, no. 1-3, pp. 196-207, 2006.

[5] E. Martínez-Carballo, C. González-Barreiro, S. Scharf, and O. Gans, "Environmental monitoring study of selected veterinary antibiotics in animal manure and soils in Austria," Environmental Pollution, vol. 148, no. 2, pp. 570-579, 2007.

[6] X. O. Shu, M. S. Linet, R. N. Gao et al., "Chloramphenicol use and childhood leukaemia in Shanghai," Lancet, vol. 2, no. 8565, pp. 934-937, 1987.

[7] M. Isildar, J. J. Jimenez, G. K. Arimura, and A. A. Yunis, "DNA damage in intact cells induced by bacterial metabolites of chloramphenicol," American Journal of Hematology, vol. 28, no. 1, pp. 40-46, 1988.

[8] M. I. Lopez, J. S. Pettis, I. B. Smith, and P. S. Chu, "Multiclass determination and confirmation of antibiotic residues in honey using LC-MS/MS," Journal of Agricultural and Food Chemistry, vol. 56, no. 5, pp. 1553-1559, 2008.

[9] W. Xu, G. Zhang, X. Li et al., "Occurrence and elimination of antibiotics at four sewage treatment plants in the Pearl River Delta (PRD), South China," Water Research, vol. 41, no. 19, pp. 4526-4534, 2007.
[10] L. Tong, P. Li, Y. Wang, and K. Zhu, "Analysis of veterinary antibiotic residues in swine wastewater and environmental water samples using optimized SPE-LC/MS/MS," Chemosphere, vol. 74, no. 8, pp. 1090-1097, 2009.

[11] B. Berendsen, L. Stolker, J. De Jong et al., "Evidence of natural occurrence of the banned antibiotic chloramphenicol in herbs and grass," Analytical and Bioanalytical Chemistry, vol. 397, no. 5, pp. 1955-1963, 2010.

[12] I. Ali, V. K. Gupta, P. Singh, H. V. Pant, and H. Y. AboulEnein, "Fast screening of chloramphenicol in wastewater by high performance liquid chromatography and solid phase extraction methods," Journal of Liquid Chromatography and Related Technologies, vol. 31, no. 18, pp. 2862-2878, 2008.

[13] A. P. Pfenning, J. E. Roybal, H. S. Rupp, S. B. Turnipseed, S. A. Gonzales, and J. A. Hurlbut, "Simultaneous determination of residues of chloramphenicol, florfenicol, florfenicol amine, and thiamphenicol in shrimp tissue by gas chromatography with electron capture detection," Journal of AOAC International, vol. 83, no. 1, pp. 26-30, 2000.

[14] L. Codognoto, E. Winter, K. M. Doretto, G. B. Monteiro, and S. Rath, "Electroanalytical performance of self-assembled monolayer gold electrode for chloramphenicol determination," Microchimica Acta, vol. 169, no. 3, pp. 345-351, 2010.

[15] S. Chuanuwatanakul, O. Chailapakul, and S. Motomizu, "Electrochemical analysis of chloramphenicol using borondoped diamond electrode applied to a flow-injection system," Analytical Sciences, vol. 24, no. 4, pp. 493-498, 2008.

[16] C. Y. Liao, C. C. Chang, C. Ay, and J. M. Zen, "Flow injection analysis of chloramphenicol by using a disposable wall-jet ring disk carbon electrode," Electroanalysis, vol. 19, no. 1, pp. 6570, 2007.

[17] S. Impens, W. Reybroeck, J. Vercammen et al., "Screening and confirmation of chloramphenicol in shrimp tissue using ELISA in combination with GC-MS ${ }^{2}$ and LC-MS ," Analytica $^{2}$ Chimica Acta, vol. 483, no. 1-2, pp. 153-163, 2003.

[18] C. Schirmer and H. Meisel, "Molecularly imprinted polymers for the selective solid-phase extraction of chloramphenicol," Analytical and Bioanalytical Chemistry, vol. 392, no. 1-2, pp. 223-229, 2008. 
[19] C. Schirmer and H. Meisel, "Chromatographic evaluation of polymers imprinted with analogs of chloramphenicol and application to selective solid-phase extraction," Analytical and Bioanalytical Chemistry, vol. 394, no. 8, pp. 2249-2255, 2009.

[20] L. Y. Guo, M. Guan, C. Zhao, and H. Zhang, "Molecularly imprinted matrix solid-phase dispersion for extraction of chloramphenicol in fish tissues coupled with highperformance liquid chromatography determination," Analytical and Bioanalytical Chemistry, vol. 392, no. 7-8, pp. 14311438, 2008.

[21] R. Mohamed, J. Richoz-Payot, E. Gremaud et al., "Advantages of molecularly imprinted polymers LC-ESI-MS/MS for the selective extraction and quantification of chloramphenicol in milk-based matrixes. Comparison with a classical sample preparation," Analytical Chemistry, vol. 79, no. 24, pp. 95579565, 2007.

[22] B. Boyd, H. Björk, J. Billing et al., "Development of an improved method for trace analysis of chloramphenicol using molecularly imprinted polymers," Journal of Chromatography A, vol. 1174, no. 1-2, pp. 63-71, 2007.

[23] M. L. Mena, L. Agüí, P. Martinez-Ruiz, P. Yáñez-Sedeño, A. J. Reviejo, and J. M. Pingarrón, "Molecularly imprinted polymers for on-line clean up and preconcentration of chloramphenicol prior to its voltammetric determination," Analytical and Bioanalytical Chemistry, vol. 376, no. 1, pp. 1825, 2003.

[24] J. L. Suárez-Rodríguez and M. E. Díaz-García, "Fluorescent competitive flow-through assay for chloramphenicol using molecularly imprinted polymers," Biosensors and Bioelectronics, vol. 16, no. 9-12, pp. 955-961, 2001.

[25] W. Thongchai, B. Liawruangath, S. Liawruangrath, and G. M. Greenway, "A microflow chemiluminescence system for determination of chloramphenicol in honey with preconcentration using a molecularly imprinted polymer," Talanta, vol. 82 , no. 2, pp. 560-566, 2010.

[26] M. C. Icardo, M. Misiewicz, A. Ciucu, J. V. García Mateo, and J. Martínez Calatayud, "FI-on line photochemical reaction for direct chemiluminescence determination of photodegradated chloramphenicol," Talanta, vol. 60, no. 2-3, pp. 405-414, 2003.

[27] J. C. Chen, J. L. Shih, C. H. Liu, M. Y. Kuo, and J. M. Zen, "Disposable electrochemical sensor for determination of nitroaromatic compounds by a single-run approach," Analytical Chemistry, vol. 78, no. 11, pp. 3752-3757, 2006.

[28] P. Yáñez-Sedeño, J. M. Pingarrón, J. Riu, and F. X. Rius, "Electrochemical sensing based on carbon nanotubes," Trends in Analytical Chemistry, vol. 29, no. 9, pp. 939-953, 2010.

[29] K. Choi, Y. Kim, J. Jung et al., "Occurrences and ecological risks of roxithromycin, trimethoprim, and chloramphenicol in the Han River, Korea," Environmental Toxicology and Chemistry, vol. 27, no. 3, pp. 711-719, 2008.

[30] F. Omil, J. M. Garrido, B. Arrojo, and R. Méndez, "Anaerobic filter reactor performance for the treatment of complex dairy wastewater at industrial scale," Water Research, vol. 37, no. 17, pp. 4099-4108, 2003.

[31] R. Hirsch, T. Ternes, K. Haberer, and K. L. Kratz, "Occurrence of antibiotics in the aquatic environment," Science of the Total Environment, vol. 225, no. 1-2, pp. 109-118, 1999.

[32] R. J. Ansell, "Molecularly imprinted polymers in pseudoimmunoassay," Journal of Chromatography B, vol. 804, no. 1, pp. 151-165, 2004.

[33] D. Satinsky, P. Chocholous, M. Salabova, and P. Solich, "Simple determination of betamethasome and chloramphenicol in a pharmaceutical preparation using a short monolithic comloumn couples to a sequential injection system," Journal of Separation Science, vol. 29, no. 16, pp. 2494-2499, 2006.

[34] C. Zhang, S. Wang, G. Fang, Y. Zhang, and L. Jiang, "Competitive immunoassay by capillary electrophoresis with laser-induced fluorescence for the trace detection of chloramphenicol in animal-derived foods," Electrophoresis, vol. 29, no. 16, pp. 3422-3428, 2008.

[35] R. Stidl and M. Cichna-Markl, "Sample clean-up by solgel immunoaffinity chromatography for determination of chloramphenicol in shrimp," Journal of Sol-Gel Science and Technology, vol. 41, no. 2, pp. 175-183, 2007.

[36] J. Yuan, J. Addo, M. I. Aguilar, and Y. Wu, "Surface plasmon resonance assay for chloramphenicol without surface regeneration," Analytical Biochemistry, vol. 390, no. 1, pp. 97-99, 2009.

[37] J. Yuan, R. Oliver, M. I. Aguilar, and Y. Wu, "Surface plasmon resonance assay for chloramphenicol," Analytical Chemistry, vol. 80, no. 21, pp. 8329-8333, 2008.

[38] I. Ali, H. Y. Aboul-Enein, V. K. Gupta, P. Singh, and U. Negi, "Analyses of chloramphenicol in biological samples by HPLC," Analytical Letters, vol. 42, no. 10, pp. 1368-1381, 2009. 


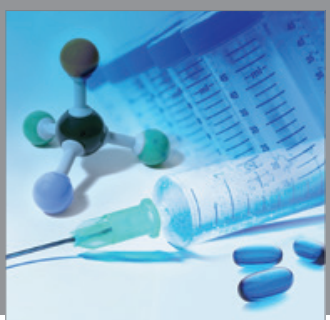

International Journal of

Medicinal Chemistry

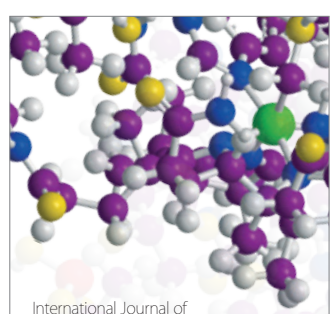

Carbohydrate Chemistry

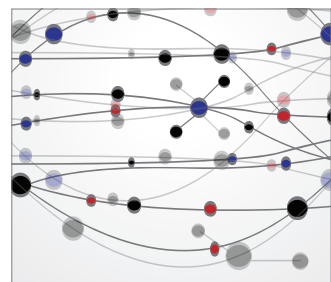

The Scientific World Journal
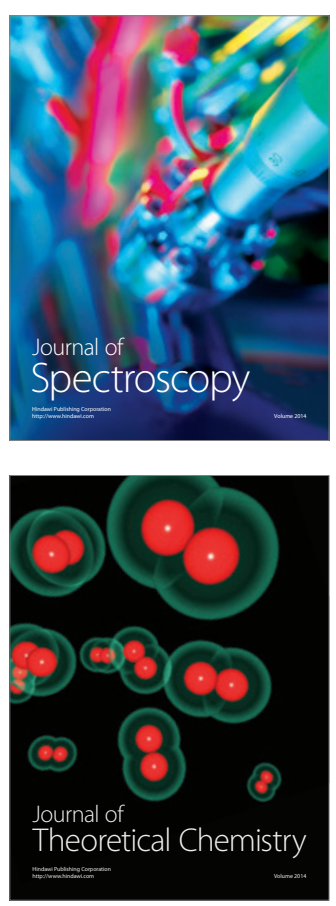
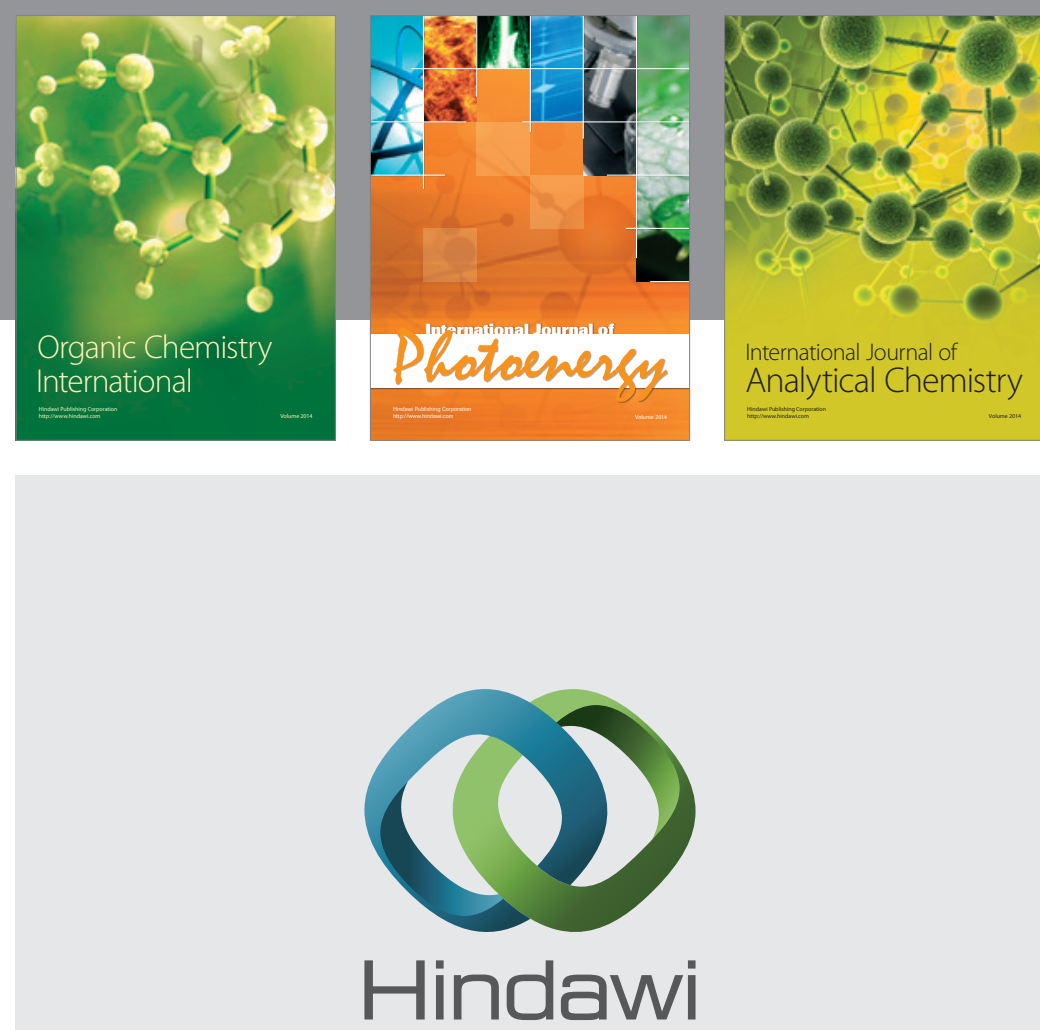

Submit your manuscripts at

http://www.hindawi.com
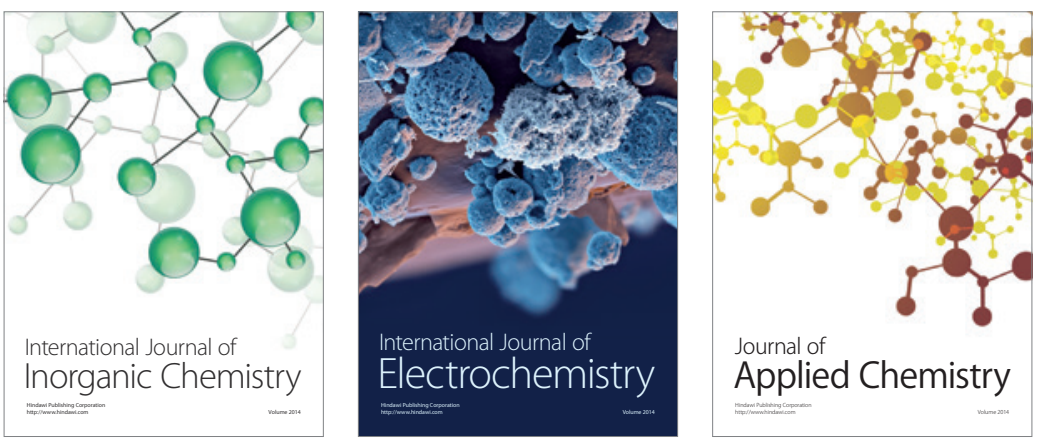

Journal of

Applied Chemistry
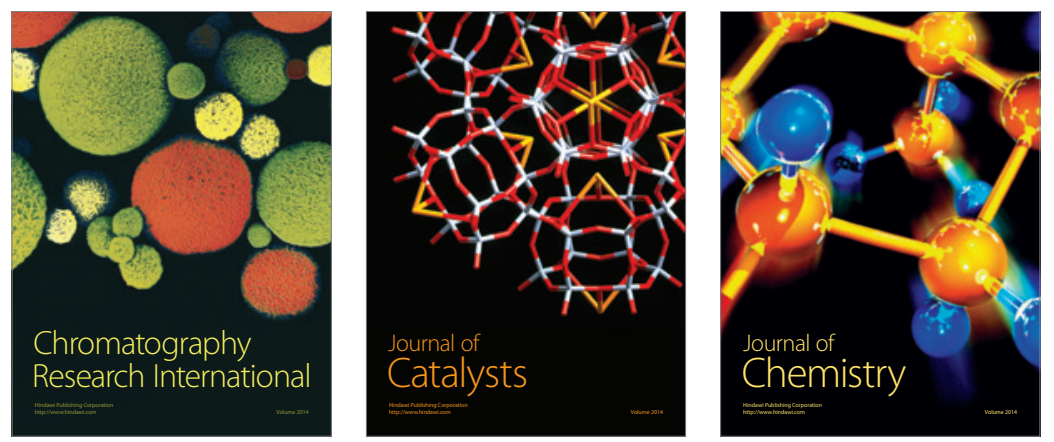
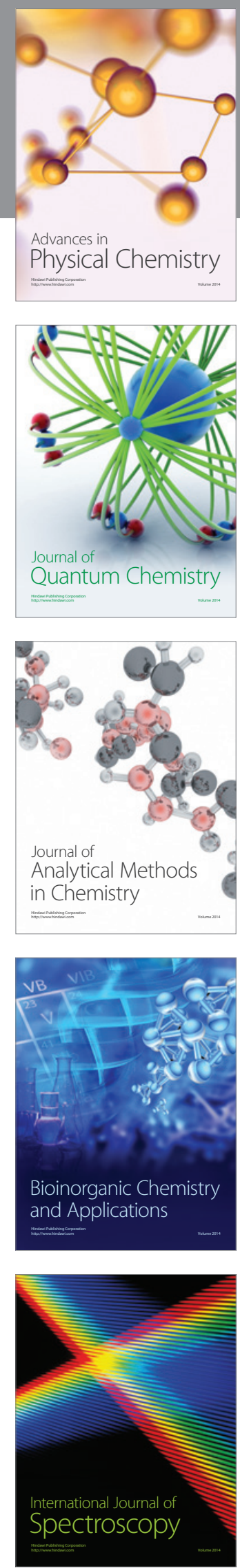